УДК 796.894:378

\title{
ВАЛЕРІЙ ЖАМАРДІЙ
}

Вищий навчальний заклад «Українська медична стоматологічна академія», м. Полтава

\section{КЛАСИФІКАЦІЙНА ХАРАКТЕРИСТИКА ЗМІСТУ ТА СТРУКТУРИ СУЧАСНИХ ФІТНЕС-ТЕХНОЛОГІЙ}

\begin{abstract}
У статті розглядається класифікаційна характеристикта змісту та структури сучасних фітнестехнологій. 3'ясовано, що важливою складовою покращання стану здоров'я та рівня фізичної підготовленості студентів $€$ застосування сучасних фітнес-технологій, які можуть сприяти вдосконаленню освітнього процесу з фізичного виховання у закладах вищої педагогічної освіти. Визначено, що в освітньому процесі з фізичного виховання фітнес-технології застосовуються через фітнес-програми як форми рухової активності, спеціально організовані в межах групових, або індивідуальних занять. Вони можуть мати оздоровчо-кондиційну спрямованість і направлені на розвиток фізичних якостей студентів до розв'язання рухових і спортивних завдань на високому рівні. Досліджено, що головною умовою застосування фітнес-технологій $є$ досягнення їх ефективності та комплексності оздоровчої спрямованості, тобто підвищення рівня фізичного, психічного та соціального здоров'я студентів за рахунок чіткого диференціювання навантаження, вибору засобів і методів проведення занять. Це дає можливість викладачам із фізичного виховання покращити фізичний розвиток студентів, використовувати розглянуті фітнес-програми з оздоровчою метою.
\end{abstract}

Ключові слова: класифікація, студенти, фізична підготовленість, фізичне виховання, фітнес, фітнес-програми, фітнес-технології

Постановка проблеми. Еволюційні процеси в сучасному українському суспільстві детермінують зміну пріоритетів у закладах вищої педагогічної освіти. Великого значення набувають сучасні вимоги до стану здоров'я та рівня фізичної підготовленості студентів, які не лише визначають, що вони повинні знати, вміти та якими фізичними якостями володіти, але й розробити таку концепцію навчання, яка була б спрямована на досягнення оптимального стану здоров'я, соціокультурної відповідності, гуманізму й особистісно орієнтованого підходу до кожного студента. Сучасна педагогічна освіта характеризується суттєвими модернізаційними змінами, що передбачають пошук інноваційних методів і форм проведення занять. Актуалізується потреба в оновленні змісту навчальних занять із фізичного виховання, що зумовлюється програмовими змінами організації навчання у закладах вищої освіти загалом і закладах вищої педагогічної освіти України, зокрема.

Аналіз досліджень і публікацій. Результати аналізу наукових праць (Ю.І. Беляк, 2014; М.М. Булатова, 2004, 2008; Є.3. Добродуб \&, Є. А. Захаріна, 2012; В.І. Григорьєв, 2010; А.В. Гурвіч, 2007; 0.А. Качан, 2017; О.Я. Кібальнік , 2008; Т.Ю. Круцевич , 2003; В.В. Левицький 2000; О.Т. Литвин , 2004; Т.С. Лісіцкая , 2002; О.В. Мартинюк, 2016; Н.В. Москаленко , 2009; О.Г. Сайкіна, 2009, 2011; С.В. Синиця, 2010; О.В. Соколова, 2010; О.Н.Степанова, 2015; С.В.Трачук, 2014; Е.Т.Хоулі, 200; Л.Є.Шестерова, 2010 та ін.) дозволили встановити, що на сьогодні детально розглянуто окремі аспекти застосування фітнес-технологій на заняттях із фізичного виховання студентів. За всієї різновекторності проблематики, комплексного дослідження проблеми застосування фітнес-технологій на заняттях із фізичного виховання студентів у закладах вищої педагогічної освіти вітчизняними дослідниками здійснено ще не було.

Мета статті полягає у термінологічному оформленні та здійсненні класифікаційної характеристикти змісту та структури сучасних фітнес-технологій.

Виклад основного матеріалу. Фітнес-технології $є$ узагальненим, інтегративним поняття усього сучасного спектру фітнес-послуг, що визначаються руховою активністю оздоровчої спрямованості та включають велику кількість новітніх напрямів і видів фітнес-програм, які відрізняються змістом і характером застосування. Це пояснюється постійною зміною приорітетів у виборі засобів для проведення занять і прагненням тих, хто займається до покращання оздоровчих послуг. Завдяки такому різноманіттю напрямів і видів фітнес-технологій на сьогодні не існує їх єдиної класифікації (Синиця, Шестерова, 2010).

Фітнес-технології мають розгалужену та ступеневу структуру, де кожний із виділених самостійних напрямів поділяється на певні різновиди. Аналізуючи виникнення фітнес-технологій, їх витоки та сучасний зміст О.Г Сайкіна $(2009 ; 2011)$ відзначає, що найбільше їх з'являється у фітнес-індустрії, яка розвиваючись швидкими темпами бере для вирішення своїх завдань усе найцінніше в оздоровчій фізичній культурі (основою є як традиційні, так і інноваційні методики, програми, технології та ін.), модернізує їх і на цій основі створює фітнес-технології. А.В. Гурвіч (2007), О.А. Качан (2017), Т.Ю. Круцевич (2003), В.В. Левицький (2000), О.Г. Сайкіна \& Г.Н. Пономарьов (2011), С.В. Синиця \&Л.Є. Шестерова (2010) та ін. переконані, що велику кількість різновидів фітнес-програм можна об’єднати в чотири основні напрями (рис. 1.). 


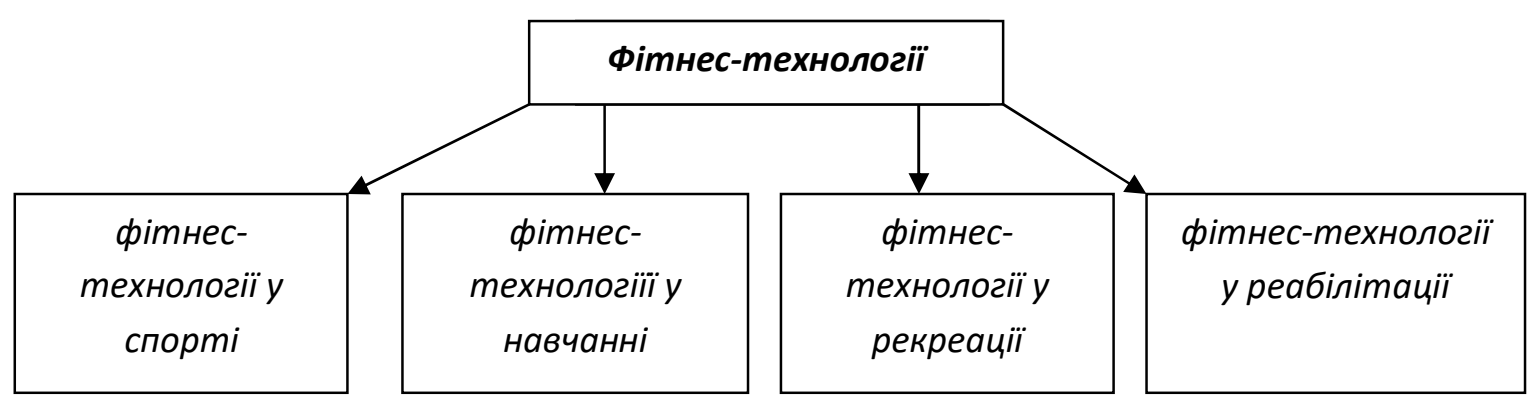

Рис. 1. Класифікація сучасних фітнес-технологій

Фітнес-технології у спорті задовольняють потреби студентів у самореалізації власних фізичних можливостей, комунікації та соціалізації, сприяють переключенню уваги з навчальної на тренувальну діяльність, отриманню від занять задоволення та позитивних емоцій, підтримання гарної спортивної форми засобами фітнесу. Основна мета їх полягає у формуванні особистої фізичної культури студентів, спеціальних знань, умінь і навичок із фітнесу, залученні їх до суспільно-історичного досвіду, освоєнні цінностей фізичної культури. Фітнес-технології можуть використовувати спортсмени під час розминки, загальної та спеціальної фізичної підготовки, психологічного розвантаження та відновлення працездатності після тренувань і змагань.

Фітнес-технології у навчанні підвищують якість проведення традиційних занять із фізичного виховання, задовольняють потреби студентів у зміцненні здоров'я, формуванні позитивного й активного ставлення до здорового способу життя, сприяють успішності навчання, відповідності сучасному стилю життя, фізичному розвитку та фізичній підготовленості. Основна мета їх полягає у формуванні усвідомленого ставлення до занять, готовності до оздоровлення організму за допомогою фізичних навантажень, потреби в систематичних заняттях фізичними вправами та дотримання основ здорового способу життя. Фітнес-технологій у фізкультурній освіті можуть використовуватися у всіх їі напрямах: дошкільній, початковій, середній, професійній і спеціальній освіті.

Фітнес-технології у рекреації являють собою широке застосування засобів оздоровчої фізичної культури та фітнесу, спрямованих на популяризацію здорового способу життя, відновлення фізичного та психічно-емоційного стану студентів, що досягається шляхом організації активного відпочинку, цікавого проведення дозвілля, зміни виду діяльності, отримання задоволення, спілкування. Основна мета їх полягає у засвоєнні основних видів і форм рекреаційної діяльності. Застосування фітнес-технологій у рекреації зумовлюється включенням студентів у різні види рекреаційної діяльності, можливістю задоволення особистісних інтересів, вибору методів і засобів проведення занять, сприяють відновленню організму.

Фітнес-технології у реабілітації призначені для студентів із обмеженими фізичними можливостями, які мають постійну, або тимчасову дисфункцію організму, низький стан здоров'я з метою компенсації пошкоджених функцій організму й урізноманітнення побутового життя засобами фітнесу. Такі заняття можуть мати лікувальну, профілактичну та спортивну (інвалідний спорт) спрямованість. Основна мета їх полягає у застосуванні природних та екологічних чинників, що стимулюють відновлення пошкоджених функцій організму, уміння використовувати фітнес-програми в навчально-тренувальній діяльності.

Класифікація сучасних фітнес-технологій в освітньому процесі з фізичного виховання передбачає їх розподіл відповідно до наступних показників: цільова, функціональна спрямованість, організаційнометодична форма проведення занять, засоби, ступінь навантаження, віковий і статевий склад, рівень фізичної підготовленості, місце проведення занять, кількісний склад, технічна забезпеченість занять (Зинченко, Усачов, 2011; Круцевич, 2003; Синиця. Шестеров, 2010).

Фітнес-технології можна розглядати як новий етап в освітньому процесі з фізичного виховання, які модернізуються з урахуванням запитів сучасного суспільства у новітній і найбільш перспективний напрям. За даними науковців, до структурно-логічної схеми фітнес-технологій входить інформаційний і практичний компоненти. Перший містить відомості про термінологічний апарат, знання про здоров'я та здоровий спосіб життя, вплив напрямів фітнесу на організм, відомості щодо раціонального харчування, методів загартовування та відновлення організму, формування основ фізкультурної освіти студентів. Практичний компонент містить інформацію щодо використовуваних засобів оздоровчого тренування (загальнорозвиваючі та гімнастичні вправи, базові елементи аеробіки, музичної ритміки та хореографії, елементи спортивних ігор, вправи у воді, єдиноборства) (Зинченко, Усачов, 2011).

В освітньому процесі з фізичного виховання фітнес-технології застосовуються через фітнес-програми як форми рухової активності, спеціально організовані в межах групових, або індивідуальних (персональних) занять. Вони можуть мати оздоровчо-кондиційну спрямованість (зниження розвитку захворювань, досягнення та підтримання оптимального рівня фізичного стану), або спрямовані на розвиток фізичних якостей студентів до розв'язання рухових і спортивних завдань на високому рівні (Булатова, Усачов, 2008; Качан, 2017; Круцевич, 2003; Москаленко, 2009; Синиця, Шестакова, 2010; Хоули, Френкс, 2000). 
За даними Т.Ю. Круцевич (2003), В.В. Левицького (2000), фітнес-технології можуть бути класифіковані на програми, які побудовані: на одному виді рухової активності (наприклад, аеробіки, оздоровчому бігу, плаванні, тощо); на поєднанні декількох видів рухової активності (наприклад, аеробіки та бодібілдингу; аеробіки та стретчингу; на оздоровчому плаванні та силовій підготовці тощо); на поєднанні одного, або декількох видів рухової активності та різних чинників здорового способу життя (наприклад, на аеробіці та загартуванні; на бодібілдингу та масажі; на оздоровчому плаванні та SPA тощо).

У свою чергу, фітнес-програми, побудовані на одному виді рухової активності, можуть бути розділені на програми, в основу яких покладені: види рухової активності аеробної спрямованості; оздоровчі види гімнастики; види рухової активності силової спрямованості; види рухової активності у воді; засоби психоемоційної регуляції. Можна виділити інтегративні, узагальнені фітнес-програми, що орієнтовані на спеціальні групи населення: програми для дітей; програми для літніх людей; програми для вагітних; програми для осіб із високим ризиком захворювань, або тих, хто мають захворювання; програми для корекції маси тіла.

На думку О.Г. Сайкіної, фітнес-програми можна розподілити на сім груп. До першої групи належать оздоровчі системи давньосхідної культурної традиції (йога, цигун), а також східні бойові мистецтва (карате, ушу, айкідо). До другої групи належать авторські оздоровчі методики (системи) відомі найчастіше за іменами їх творців, такі як дихальна гімнастика за методом А.М. Стрельнікової, система пілатес (засновник - Дж. Пілатес). У третю групу можна об’єднати різні оздоровчі системи, що грунтуються на основі наукових досягнень й апробовані на практиці. Вони пов'язані з використанням засобів, відмінних від традиційних (шейпінг, аерофітнес та ін.). До четвертої групи відносяться нові форми рухової активності: ритмічна гімнастика, аеробіка, стретчинг, фітбол. До п’ятої групи відносяться інноваційні технології й авторські програми, які апробовані та користуютсья популярністю («са-фі данс», «фітбол-гімнастика», «ігровий стретчинг»). Шоста група представлена циклічними видами рухів: оздоровча ходьба, плавання, їзда на велосипеді, заняття на тренажерах. До сьомої групи відносять спортивні та рухливі ігри (Сайкина, 2009).

Висновки. Аналіз світового досвіду та результатів наукових досліджень переконує, що ефективною складовою підвищення рівня рухової активності студентів може стати створення та впровадження в освітній процес із фізичного виховання різноманітних і найбільш популярних фітнес-програм оздоровчого, кондиційного та спортивного напрямів як універсального виду фізичних навантажень. Головною умовою застосування фітнес-технологій є досягнення їх ефективності та комплексності оздоровчої спрямованості, тобто підвищення рівня фізичного, психічного та соціального здоров'я за рахунок чіткого диференціювання навантаження, вибору засобів і методів проведення занять. Це дає можливість викладачам із фізичного виховання використовувати розглянуті фітнес-програми з оздоровчою метою. Перспективи подальших досліджень із даного напряму полягають у розробці програмно-методичного забезпечення освітнього процесу з фізичного виховання у закладах вищої педагогічної освіти.

\section{Список використаних джерел}

Беляк, Ю. (2014) Класифікація та методичні особливості засобів оздоровчого фітнесу. Педагогіка, психологія та медико-біологічні проблеми фізичного виховання і спорту. 11, 3-8.

Булатова, М. М., Литвин, О.Т. (2004). Здоров'я і фізична підготовленість населення України. Теорія $i$ методика фізичного виховання і спорту, 1, 3-9.

Булатова, М. М., Усачов, Ю.О. (2008) Сучасні фізкультурно-оздоровчі технології у фізичному вихованні. Теорія $i$ методика фізичного виховання. (320-354). Київ : Олімпійська література.

Григорьев, В. И., Давидеко, Д. Н., Малинина, С.В. (2010). Фитнес-культура студентов : теория и практика : учеб. пособие Санкт-Петербург : Изд- во СПб. ГУЭФ.

Гурвич, А. В. (2007) Применение инновачионных фитнес-технологий в военно-образовательных учреждениях и спортивных клубах для поддержания здорового образа жизни (Диссертация ... кандидата педагогических наук : 13.00.04). Санкт-Петербург.

Добродуб, Є.З., Захаріна, Є.А. (2012). Теорія та методика оздоровчого фітнесу: методичні рекомендаиії до виконання практичних занять для студентів денної форми навчання. Запоріжжя : КПУ.

Зинченко, В. Б., Усачов, Ю.О. (2011). Фитнес-технологии в физическом воспитании : учеб. пособие Киев : НАУ.

Качан, О.А. (2017). Упровадження інновачійних технологій у фізкультурно-оздоровчу та спортивну діяльність закладів освіти : навчально-методичний посібник. Слов'янськ : Витоки, 2017.

Кібальнік О.Я. (2008). Застосування фітнес-технологї для підвищення рухової активності та фізичної nідготовленості підлітків (автореф. дис. на здобуття наукового ступеню канд. наук з фіз. вих. і спорту : спец. 24.00 .02 «Фізична культура, фізичне виховання різних груп населення»). Київ.

Круцевич, Т. Ю. (2003). Теория и методика физического воспитания. Киев: Олимпийская література. Том 1.

Круцевич Т. Ю. (2003). Теория и методика физического воспитания / Киев: Олимпийская література. Том 2.

Левицкий, В. В. (2000). Методология подготовки специалистов по оздоровительной физической культуре. Наука в олимпийском спорте : Специальный выпуск ГНИИФКС. ( 89-96).

Лисицкая, Т. С., Сиднева, Л.И. (2002). Аэробика. Теория и практика (Т. 1,2.) - Москва: Федерация аэробики. Мартинюк,О. Функціональний стан жінок першого періоду зрілого віку в процесі занять оздоровчим фітнесом. Молодіжний науковий вісник Східноєвропейського національного університету імені Лесі Украӥнки. Серія : Фізичне виховання і спорт. Луцьк. Вип. 22.

Москаленко, Н. В. (2009). Теоретико-медологічні засади інновачійних технологій в системі фізичного виховання молодиих школярів (Автореф. дис. ... д-ра наук з фіз. виховання і спорту : 24.00.02). Київ. 
Мулик, К. В., Максимова, К.В. (2017) Культурологічна еманація фітнес-культури як засіб оздоровлення студентської молоді. Педагогіка та психологія. Вип. 58, 71-82.

Савин, С.В., Степанова, О.Н. (2015). Педагогическое проектирование занятий фитнесом с лицами зрелого возраста : монографія. Москва : УЦ Перспектива.

Сайкина, Е. Г., Пономарев, Г.Н. (2011). Семантические аспекты отдельных понятий в области фитнеса. Теория $u$ практика физической культуры : науч.- теор. журнал, 6-10.

Сайкина, Е. Г. (2009). Фитнес в системе дошкольного и школьного физкультурного образования (Диссертация ... доктора педагогических наук : 13.00.04). Санкт-Петербург.

Синиця С. В., Шестерова Л. В. (2010). Оздоровча аеробіка. Спортивно-педагогічне вдосконалення : навч. посіб. Полтава : ПНПУ.

Соколова ,О. В. Использование дозированных физических нагрузок в повышении физического здоровья и функционального состояния кардиореспираторной системы организма студентов 18-19 лет. Педагогіка, психологія і медико-біологічні проблеми фізичного виховання і спорту : наук, монографія. Харків.

Трачук, С. (2014). Фізична підготовленість школярів 13-14 років впродовж навчального року. Фізичне виховання 8 контексті сучасної освіти, матеріали ІХ Міжнародної науково-практичної конференції студентів і аспірантів. -Київ: НАУ.

Хоули, Эдвард Т., Френкс, Дон Б. (2000). Оздоровительный фітнес. Киев: Олимпийская література.

\section{References}

Beliak, Yu. I. (2014). Klasyfikatsiia ta metodychni osoblyvosti zasobiv ozdorovchoho fitnesu [Pedahohika, psykholohiia ta medyko-biolohichni problemy fizychnoho vykhovannia i sportu]. Classification and methodical features of the means of health fitness [Pedagogics, psychology and medical and biological problems of physical education and sports], № 11, 3-8. [in Ukrainian].

Bulatova, M. M. (2004). Zdorovia i fizychna pidhotovlenist naselennia Ukrainy [Teoriia i metodyka fizychnoho vykhovannia i sportu]. Health and physical preparedness of the population of Ukraine [Theory and methods of physical education and sport], № 1, 3-9. [in Ukrainian].

Bulatova, M. M. (2008). Suchasni fizkulturno-ozdorovchi tekhnolohii u fizychnomu vykhovanni [Modern physical culture and health technologies in physical education]. Kyiv: Olimp. 1-ra [in Ukrainian].

Grigor'ev, V. I. (2010). Fitnes-kul'tura studentov: teorija i praktika: ucheb. posobie. [Physical culture of students: theory and practice: study. Allowance]. Sankt-Peterburg [in Russian].

Gurvich, A. V. (2007). Primenenie innovacionnyh fitnes-tehnologij v voenno-obrazovatelnyh uchrezhdenijah i sportivnyh klubah dlja podderzhanija zdorovogo obraza zhizni (dis ... kand. ped. nauk: 13.00.04). [Application of innovative fitness technologies in military educational establishments and sports clubs for maintenance of a healthy way of life [PhD thesis)]. Sankt-Peterburg [in Russian].

Dobrodub, Ye. Z. (2012). Teoriia ta metodyka ozdorovchoho fitnesu: metodychni rekomendatsii do vykonannia praktychnykh zaniat dlia studentiv dennoi formy navchannia. [Theory and methodology of health fitness: methodical recommendations for the implementation of practical classes for full-time students]. Zaporizhia: KPU [in Ukrainian].

Zynchenko, V. B. (2011). Fytnes-tekhnolohyy v fyzycheskom vospytanyy: ucheb. posobye. [Fitness technology in physical education: Textbook. Allowance]. Kyiv: NAU [in Russian].

Kachan, O. A. (2017). Uprovadzhennia innovatsiinykh tekhnolohii u fizkulturno-ozdorovchu ta sportyvnu diialnist zakladiv osvity: navchalno-metodychnyi posibnyk. [Implementation of innovative technologies in physical culture and health and sports activities of educational institutions: a teaching manual]. Slovyansk: Vytoky [in Ukrainian].]

Kybalnik, O. Ya. (2008). Zastosuvannia fitnes-tekhnolohii dlia pidvyshchennia rukhovoi aktyvnosti ta fizychnoi pidhotovlenosti pidlitkiv (avtor. kand. nauk z fiz. vykh. i sportu: 24.00.02). [Application of fitness technology to increase motor activity and physical fitness of adolescents [PhD thesis)]. Kyiv [in Ukrainian].

Krutsevych, T. Yu. (2003). Teorija i metodika fizicheskogo vospitanija. [Theory and method of physical education]. Kyiv: Olimp. 1-ra [in Russian].

Krutsevych, T. Yu. (2003). Teorija i metodika fizicheskogo vospitanija. [Theory and method of physical education]. Kyiv: Olimp. 1-ra [in Russian].

Levitsky, V. V. (2000). Metodologija podgotovki specialistov po ozdorovitelnoj fizicheskoj kulture [Nauka v olimpijskom sporte: specialnyj vypusk GNIIFKS]. Methodology of training specialists in the field of improving physical education [Science in the Olympic sport: Special issue of GNIIFKS], 89-96. [in Russian].

Lisickaja, T. S. (2002). Ajerobika. Teorija i praktika. [Aerobics. Theory and practice]. Moscow: Federation of aerobics [in Russian].

Martyniuk, O. (2016). Funktsionalnyi stan zhinok pershoho periodu zriloho viku v protsesi zaniat ozdorovchym fitnesom [Molodizhnyi naukovyi visnyk Skhidnoievropeiskoho natsionalnoho universytetu imeni Lesi Ukrainky]. Functional state of women of the first period of mature age in the process of training with fitness [Youth scientific bulletin of the East european national university named after Lesya Ukrainka], № 22, 31-36. [in Ukrainian].

Moskalenko, N. V. (2009). Teoretyko-medolohichni zasady innovatsiinyh tekhnolohii v systemi fizychnoho vykhovannia molodshykh shkoliariv (avtor. kand. nauk z fiz. vykh. i sportu: 24.00.02). [Theoretical and medological principles of innovative technologies in the system of physical education of junior schoolchildren [ $\mathrm{PhD}$ thesis)]. Kyiv [in Ukrainian].

Mulik, K. V. (2017). Kulturolohichna emanatsiia fitnes-kultury yak zasib ozdorovlennia studentskoi molodi [Pedahohika ta psykholohiia]. Culturological emanation of fitness culture as a means of recovery of student youth [Pedagogics and psychology], № 58, 71-82. [in Ukrainian].

Savin, S. V. (2015). Pedagogicheskone proektirovanie zanjatij fitnesom s licami zrelogo vozrasta: monografija. [Pedagogical design of fitness classes with persons of mature age: monograph]. Moskva: UC Perspektiva [in Russian]. 
Saykina, E. G. (2011). Semanticheskie aspekty otdelnyh ponjatij v oblasti fitnesa [Teorija i praktika fizicheskoj kutury: nauch. teor. zhurnal]. Semantic aspects of individual concepts in the field of fitness [Theory and practice of physical culture: scientific theory. magazine], 6-10. [in Russian].

Saykina, E. G. (2009). Fitnes v sisteme doshkolnogo i shkolnogo fizkulturnogo obrazovaniya (dis ... dokt. ped. nauk: 13.00.04). [Fitness in the system of preschool and school physical education [PhD thesis)]. Sankt-Peterburg [in Russian].

Synytsia, S. V. (2010). Ozdorovcha aerobika. Sportyvno-pedahohichne vdoskonalennia: navch. posib. [Wellness aerobics. Sport and pedagogical improvement: teach. manual]. Poltava: PNPU [in Ukrainian].

Sokolova, O. V. (2010. Ispolzovanie dozirovannyh fizicheskih nagruzok v povyshenii fizicheskogo zdorovja i funkcionalnogo sostojanija kardiorespiratornoj sistemy organizma studentov 18-19 let [Pedagogika, psihologija i mediko-biologichni problemi fizichnogo vihovannja $\mathrm{i}$ sportu]. The use of metered physical loads in increasing the physical health and functional state of the cardiorespiratory system of the body of students 18-19 years [Pedagogics, psychology and medical and biological problems of physical education and sports], № 3, 86-88. [in Russian].

Trachuk, S. (2014). Fizychna pidhotovlenist shkoliariv 13-14 rokiv vprodovzh navchalnoho roku [Fizychne vykhovannia v konteksti suchasnoi osvity, materialy IX Mizhnarodnoi naukovo-praktychnoi konferentsii studentiv i aspirantiv]. Physical preparedness of schoolchildren 13-14 years during the school year [Physical education in the context of modern education materials of the IX International scientific and practical conference of students and postgraduates]. Kyiv: NAU [in Ukrainian].

Howley Edward, T. (2000). Ozdorovitelnyj fitness. [Wellness fitness]. Kyiv: Olimp. 1-ra [in Russian].

\section{ZHAMARDIY V.}

Ukrainian Medical Stomatological Academy, Poltava, Ukraine

\section{CLASSIFICATION CHARACTERISTICS OF CONTENT AND STRUCTURE OF MODERN FITNESS TECHNOLOGIES}

The article deals with the classification characteristics of the content and structure of modern fitness technologies. It has been found out that the use of modern fitness technologies is an important part of improving health and physical fitness level of students, since educational and training activities have ample opportunities for modeling the conditions and situations that can contribute to improvement of physical education process in higher institutions of pedagogical education. It is determined that in the physical education process, fitness technology is used through fitness programs as forms of motor activity, specially organized within group or individual (personal) classes. They can have a healthconditioning orientation or they can be aimed at developing physical qualities of students to solve motor and sports tasks at a high level of performance. It was investigated that the main condition for fitness technologies application is to achieve the efficiency and complexity of health improvement, that is, to increase the level of physical, mental and social health of students. Fitness technologies can be considered as a new stage of educational process in physical education. They are modernized taking into account the demands of modern society in the latest and most promising direction. The use of fitness programs in the physical education process of students will significantly improve its efficiency due to a strict differentiation of loads, the choice of means and methods of conducting classes. This enables teachers to improve physical development of students, to use the considered fitness programs with a health-improving purpose.

Key words: classification, students, physical fitness, physical education, fitness, fitness programs, fitness technologies

Стаття надійшла до редакції 18.08. 2018 р. 